\title{
Experimental study and theoretical modeling for the compressive stress-strain relationship of multi-scale hybrid fiber- reinforced SHCC
}

\author{
(C. Zhang ${ }^{\mathrm{a}, \mathrm{b}} \bowtie, \oplus Z$. Yuan ${ }^{\mathrm{a}}, \oplus \mathrm{Y} . \mathrm{Shen}^{\mathrm{c}}$ \\ a. School of Environment and Civil Engineering, Jiangnan University, (Wuxi, China) \\ b. State Key Laboratory for GeoMechanics and Deep Underground Engineering, University of Mining \& Technology, (Xuzhou, China) \\ c. School of Civil and Environmental Engineering, Nanyang Technological University, (Singapore, Singapore) \\ 凶: zhangcong@jiangnan.edu.cn
}

Received 17 April 2021

Accepted 23 August 2021

Available on line 17 February 2022

\begin{abstract}
In order to better match the multi-level structural characteristics and multi-scale fracture process of cementitious composite, multi-scale hybrid fiber-reinforced strain hardening cementitious composite (MsHySHCC) was designed by adding hooked steel fiber and calcium carbonate $\left(\mathrm{CaCO}_{3}\right)$ whisker into conventional polyvinyl alcohol (PVA) fiber-reinforced SHCC. Compressive properties of PVA-SHCC and MsHySHCC were evaluated experimentally. The results indicate that the designed MsHySHCC had a better compressive performance than that of PVA-SHCC. Moderately partially substituted PVA fibers by steela fiber and $\mathrm{CaCO}_{3}$ whisker enhanced the compressive parameters, however, further substitution of PVA fibers by increasing the content of $\mathrm{CaCO}_{3}$ whisker didn't bring a higher promotion. Two kinds of semi-theoretical compression constitutive models were developed from the perspective of damage mechanics theory and geometrical mathematical description, respectively. It was found that both of the proposed models can be applied to predict the uniaxial compressive stress-strain relationships of PVA-SHCC and MsHySHCCs.
\end{abstract}

KEYWORDS: Mortar; Fibre reinforcement; Compressive strength; Modelization; Mechanical properties.

Citation/Citar como: Zhang, C.; Yuan, Z.; Shen Y. (2021) Experimental study and theoretical modeling for the compressive stress-strain relationship of multi-scale hybrid fiber-reinforced SHCC. Mater. Construcc. 72 [345], e272. https://doi.org/10.3989/ mc.2022.06021.

RESUMEN: Estudio experimental y modelo teórico de la relación tensión-deformación en compresión de SHCC reforzado con fibras multiescala. Con el fin de combinar de la mejor forma posible las características estructurales de compuestos base cemento a varios niveles y su proceso de fractura a múltiples escalas, se diseñó un compuesto híbrido de base cemento de endurecimiento por deformación reforzado con fibras (MsHySHCC), añadiendo fibra de acero en forma de gancho y fibra de carbonato de calcio $\left(\mathrm{CaCO}_{3}\right)$ en SHCC reforzado con fibra de alcohol polivinílico convencional (PVA). Se evaluaron las propiedades a compresión de PVA-SHCC y MsHySHCC. Los resultados indican que el MsHySHCC diseñado tuvo un mejor rendimiento a compresión que el de PVA-SHCC. Las fibras de PVA sustituidas parcialmente por fibra de acero y de $\mathrm{CaCO}_{3}$ mejoraron los parámetros de compresión, sin embargo, una mayor sustitución de las fibras de PVA no causó una mejora al aumentar el contenido de fibras de $\mathrm{CaCO}_{3}$. Se desarrollaron dos tipos de modelos constitutivos de compresión semi-teóricos desde la perspectiva de la teoría de la mecánica del daño y la descripción matemática geométrica, respectivamente. Se encontró que ambos modelos propuestos se pueden aplicar para predecir las relaciones de tensión-deformación a compresión uniaxial de PVA-SHCC y MsHySHCCs

PALABRAS CLAVE: Mortero; Refuerzo de fibras; Resistencia a compresión; Modelización; Propiedades mecánicas.

Copyright: (C2022 CSIC. This is an open-access article distributed under the terms of the Creative Commons Attribution 4.0 International (CC BY 4.0) License. 


\section{INTRODUCTION}

Strain hardening cementitious composite (SHCC) has attracted wide attention in the field of civil engineering because of its ultra-high ductility and obvious characteristics of multiple cracking $(1,2)$. Recently, a variety of fibers were used to prepare SHCC, such as polyethylene (PE) fiber, polypropylene (PP) fiber, and polyvinyl alcohol (PVA) fiber (3-7). In general, PVA fiber reinforced SHCC (PVA-SHCC) have been widely studied. However, the relative high cost restricts its large-scale engineering applications.

To solve the cost issue, fiber hybridization method is usually employed $(1,8)$, especially for the hybrid use of PVA fiber and steel fiber (SF) (8-11). As is well known that cementitious materials have obvious multi-level structural characteristics, namely, cement hydration product level, cement paste level, mortar level and concrete level. These multi-level structural characteristics of cementitious materials also determine their multi-scale fracture process, i.e., the generation, development and gradual evolution of micro-cracks into macroscopic cracks, resulting in the ultimate failure of cementitious materials. Theoretically, cementitious materials can be greatly enhanced by multi-scale hybrid fibers from microscopic scale level to macroscopic scale level. But obviously, the only use of steel fiber and PVA fiber is difficult to accomplish this task. Because the geometry size of commonly adopted PVA fiber and steel fiber can't well match the microscopic scale of cement hydration product and microscopic cracks, thus can't effectively improve the microscopic properties of cementitious materials.

Recently, as a novel cheap microfiber, calcium carbonate $\left(\mathrm{CaCO}_{3}\right)$ whisker $(\mathrm{CW})$ was introduced to improve the mechanical properties of PVA-SHCC and hybrid SF/PVA-SHCC on microscopic scale level. Therefore, a new type of hybrid fiber reinforced SHCC, which is named multi-scale hybrid fiber reinforced strain hardening cementitious composite (MsHySHCC), was designed (12-25). Mechanical properties and reinforcing mechanisms of MsHySHCC have been widely investigated in previous literatures.

Ma et al. (26) studied the CW effects on the mechanical properties of PVA-SHCCs, and the results indicated that the $\mathrm{CW}$ addition improved the compressive property and tensile behavior of PVASHCC. Additionally, the robustness of tensile stressstrain curves was also significantly improved. Pan and Cai (27) investigated the mechanical properties of SHCC containing PVA fibers and CWs. Based on the observations from their study, CWs can be used to partially substitute PVA fibers. Cao et al. (12-25) studied the rheological behaviors, mechanical properties and shrinkage performances of MsHySHCC. They found that the designed MsHySHCC has very satisfactory mechanical properties.
To PVA-SHCC and MsHySHCC, the fully understand of their compressive properties and compression constitutive model is the important precondition to promote their widely application in structural design. Therefore, many scholars have evaluated the compressive properties and tried to describe the compressive constitutive relationship of SHCC and hybrid fiber reinforced SHCC from an empirical or theoretical perspective. Ding et al. (4) reported the compressive behavior of PE fiber reinforced ultra-high ductility cementitious composites with the compressive strength from $40 \mathrm{MPa}$ to $120 \mathrm{MPa}$. They found that the compressive strain at peak stress falls in the range of 3000-4000 u $\varepsilon$ and increases with the increasing compressive strength. Zhou et al. (28) studied the stress-strain behavior of PVA-SHCC in uniaxial compression. But they found the strain at peak load is between 4000 and $5000 \mathrm{u} \varepsilon$, and there is little correlation between the peak strain and the compressive strength. Yu et al. (29) studied the compressive stress-strain behavior of PE fiber reinforced ultra-high performance SHCC with a compressive strength of $120 \mathrm{MPa}$. In their study, the compressive strain corresponding to the peak stress reached 2954 uc. Xu et al. (30) investigated the compressive properties of PVA fiber reinforced ultra-high toughness cementitious composites experimentally. Their results showed that the compressive toughness and ductility were obviously improved. The average strain at peak stress was 5654 ue. Xu (30) and Zhou (28) proposed their theoretical compressive models for PVA-SHCC by using a geometry-based method, respectively. However, more damage mechanism should be taken into consideration in their compressive constitutive models.

Yun (31) reported the compressive strength and compressive stress-strain curves of hybrid PVA and PE fiber-reinforced SHCC under different water to binder ratio. The results showed that the compressive strength and the corresponding strain increased with the increasing of PE fiber content. Pourfalah (9) investigated the compressive behavior of PVASHCC and hybrid fiber reinforced SHCC. The hybrid fibers used in this study are PVA fiber and micro steel fibers. The addition of hybrid fibers increased the compressive strength and the compressive strain at peak stress. It should be noted that the compressive strains at peak stress are about $11000 \mathrm{u} \varepsilon$ in this study, which are obviously larger than those in other literatures. Wang et al. (10) studied the stress-strain behavior of PVA-steel hybrid fiber reinforced SHCC in compression. The effect of additional steel fiber content on the compressive performance was investigated. The results showed that the stress-strain behaviors of hybrid PVA-steel fiber SHCC were improved with increasing steel fiber content. A simple compressive stress-strain model was proposed by fitting their experimental data, and this model gave satisfactory predictions of the complete stress-strain 
behavior of hybrid fiber SHCC. Al-Gemeel et al. (11) reported the compressive behavior of steel fiber hybrid PVA fiber reinforced SHCC containing glass microspheres. The results showed that the mono-fiber SHCC has a higher compressive strength than hybrid fiber reinforced SHCC. From the compressive stress-strain curves, it can be found that the addition of hybrid fibers not only decreased the compressive strength of PVA-SHCC, but also decreased the strain at peak stress, which are obviously contrary to the results of Wang (10) and Pourfalah's studies (9).

From the discussions on the previous literatures, it can be found that the effects of SF-PVA hybrid fibers and SF-PVA-CW multiscale hybrid fibers on the compressive behavior of SHCC are not fully understood, and even sometimes obtained contrary conclusions in previous literatures. Moreover, the studies on the theoretical compressive constitutive models are still very limited. Although some scholars have modified the Lemaitre's damage model to describe the compression constitutive relationship of normal concrete, these existing concrete damage constitutive models are not applicable to hybrid fiber-reinforced cementitious composite, especially for hybrid fiber reinforced SHCC and MsHySHCC. Therefore, a further experimental and theoretical investigation on the compressive behavior of hybrid fiber reinforced SHCC is still needed.

In this paper, a kind of MsHySHCC was designed by adding hooked steel fiber and $\mathrm{CaCO}_{3}$ whisker into conventional PVA-SHCC. Compressive properties of PVA-SHCC and designed MsHySHCC were evaluated experimentally. The effect of steel fiber, PVA fiber and $\mathrm{CaCO}_{3}$ whisker on the compressive stress, compressive strain and compressive toughness was discussed. Based on the experimental results, a damage constitutive model and a geometrical mathematical model were proposed. Through the analysis in this paper, an in-depth understanding for compressive behavior of PVA-SHCC and MsHySH$\mathrm{CC}$ will be given, which is of great significance for their large-scale structural engineering applications in the future.

\section{EXPERIMENTAL PROCEDURE}

Raw materials for mortar matrix used in this study were ordinary Portland cement P.O 42.5, Class-I fly ash, fine quartz sand (particle size 100-210 $\mu \mathrm{m}$, mean size $150 \mu \mathrm{m}$ ) and water. The ratio of cement, quartz sand and fly ash was 1:1.8:4, and the water to binder ratio was 0.34 . The amount of superplasticizer (polycarboxylic acid type, water reducing ratio $28.3 \%$ ) was 0.5 wt. $\%$ of binder content. The multiscale hybrid fiber system was composed of steel fiber, PVA fiber and $\mathrm{CaCO}_{3}$ whisker. Their basic information was shown in Figure 1. Volume fraction of different fibers in each designed group was shown in Table 1.

Before compressive test, the tensile stress-strain curves were experimentally obtained to verify whether the designed MsHySHCCs can achieve strain-hardening behavior. Typical tensile stressstrain curves are shown in Figure 2. It can be seen that all the designed mix proportions can present an obvious tensile strain-hardening performance, especially for MsHySHCC-1 and MsHySHCC-2.

The mixing, preparation and curing processes of compression specimens are shown in Figure 3. After mixing, the fresh mixture was placed into a steel mold with size of $70.7 \mathrm{~mm} \times 70.7 \mathrm{~mm} \times 70.7 \mathrm{~mm}$, which was then vibrated on a vibration machine for 20 seconds to make the mixture dense. After 24 hours, the mold was demolded, all specimens were put into a curing box with a temperature of $20 \pm 2{ }^{\circ} \mathrm{C}$

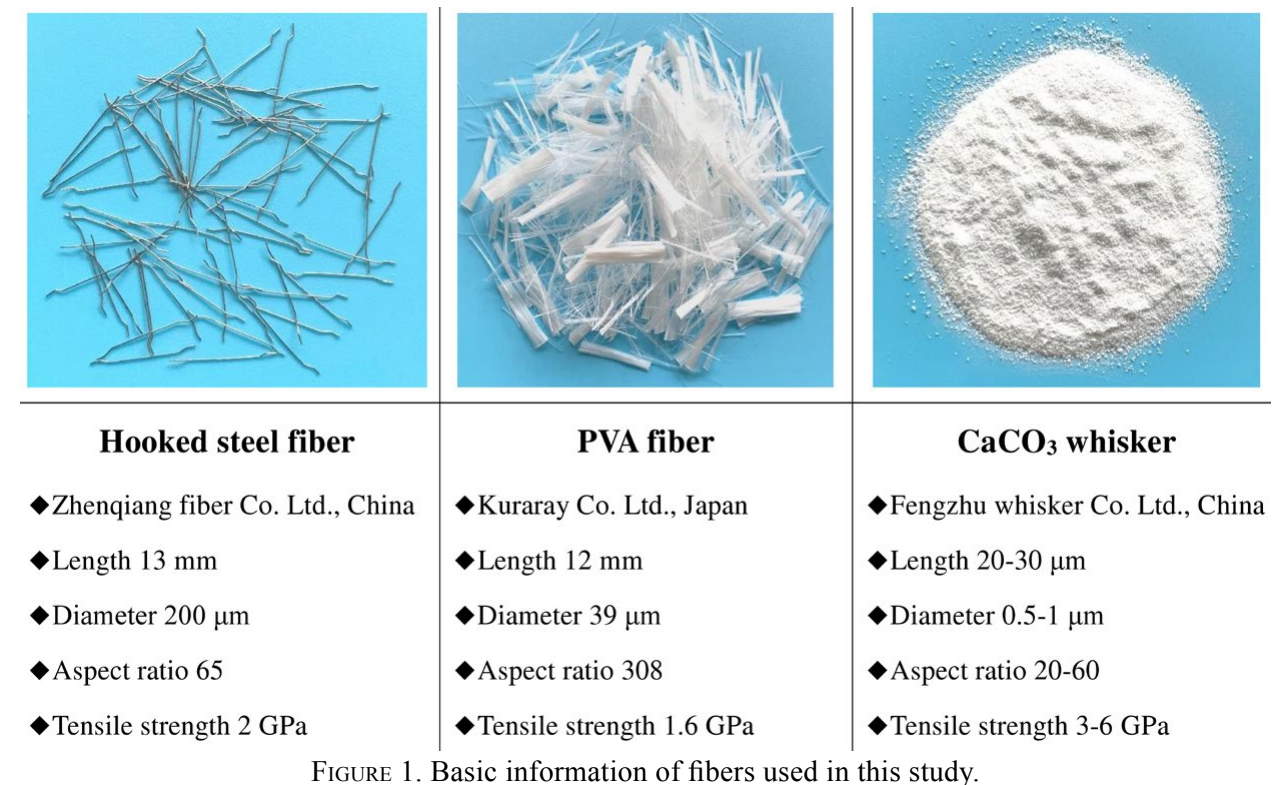

Materiales de Construcción 72 (345), January-March 2022, e272. ISSN-L: 0465-2746. https://doi.org/10.3989/mc.2022.06021 
TABLE 1. Volume fraction of different fibers in each designed groups.

\begin{tabular}{lcccc}
\hline Groups & Specification & Steel fiber $(\mathrm{SF}) / \%$ & PVA fiber (PVA) $/ \%$ & $\mathrm{CaCO}_{3}$ whisker $(\mathrm{CW}) / \%$ \\
\hline Control-1 & Matrix & 0 & 0 & 0 \\
\hline Control-2 & CW1 & 0 & 0 & 1 \\
\hline Control-3 & CW2 & 0 & 0 & 2 \\
\hline PVA-SHCC & PVA2 & 0 & 2 & 0 \\
\hline MsHySHCC-1 & SF0.25PVA1.75CW1 & 0.25 & 1.75 & 1 \\
\hline MsHySHCC-2 & SF0.5PVA1.5CW1 & 0.5 & 1.5 & 1 \\
\hline MsHySHCC-3 & SF0.75PVA1.25CW1 & 0.75 & 1.25 & 1 \\
\hline MsHySHCC-4 & SF0.25PVA1.5CW2 & 0.25 & 1.5 & 2 \\
\hline MsHySHCC-5 & SF0.5PVA1.25CW2 & 0.5 & 1.25 & 2 \\
\hline MsHySHCC-6 & SF0.75PVA1CW2 & 0.75 & 1 & 2 \\
\hline
\end{tabular}

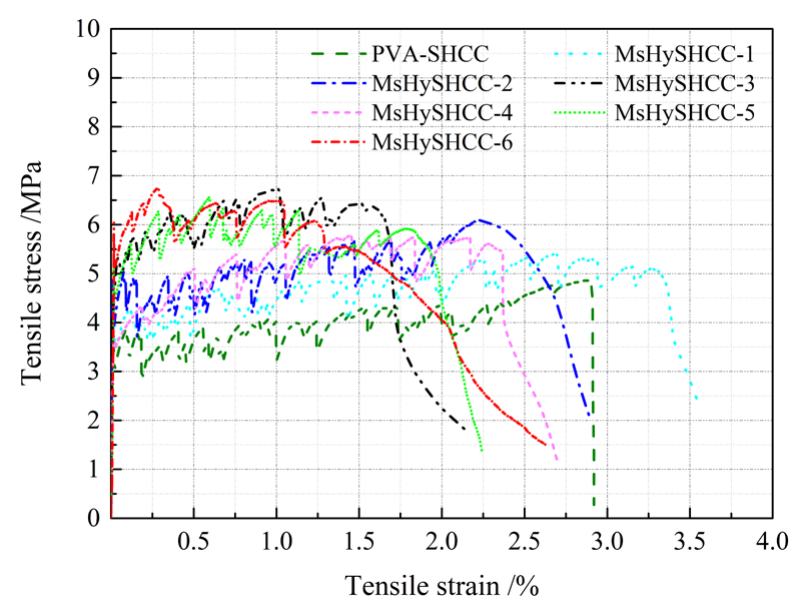

Figure 2. Typical tensile stress-strain curves of designed MsHySHCCs.

and a humidity of $95 \%$, and were kept there for 28 days. To ensure the accuracy of the experimental results, for each design mix 6 specimens were casted.
Uniaxial compression test was carried out using an electro-hydraulic servo material testing machine. The loading method was the displacement control with a rate of $0.2 \mathrm{~mm} / \mathrm{min}$. The loading instrument for the compression test is shown in Figure 4.

In order to evaluate the compressive properties (compressive strength, compressive peak strain and compressive toughness) more accurately, the Weibull distribution method was employed in this study. The standard Weibull distribution equation can be expressed as Equation [1].

$$
P=1-e^{-\left(\frac{\sigma}{\sigma_{0}}\right)^{m}}
$$

where $P$ is the failure probability; $\sigma$ is the variable parameter; $\sigma_{0}$ is the characteristic strength (also called scale parameter); $m$ is the Weibull modulus (also called shape parameter). When double logarithm transformation is used, then the Equation [1] can be further expressed as Equation [2].

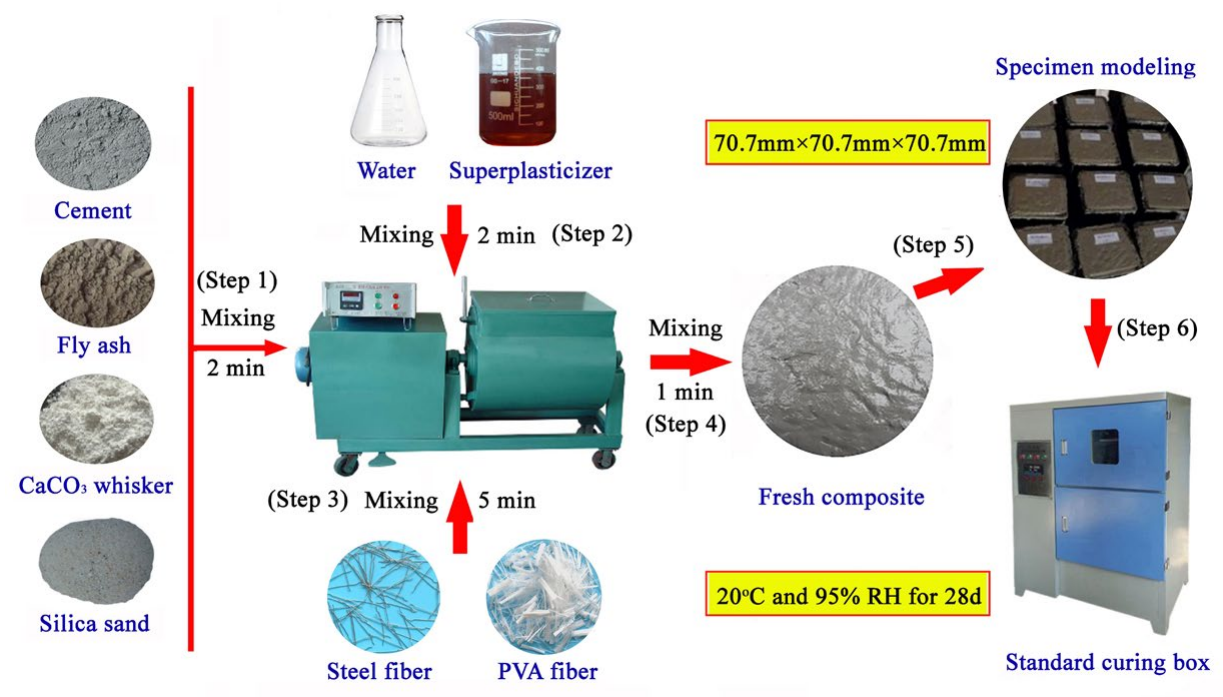

FIGURE 3. Mixing process and specimen preparation. 


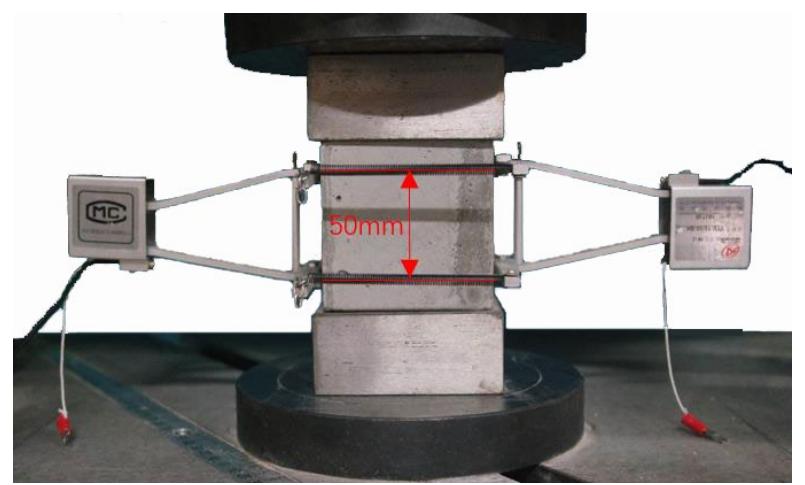

FIGURE 4. Loading setup for compression test.

$$
\ln \left[\ln \left(\frac{1}{1-P}\right)\right]=m \ln (\sigma)-m \ln \left(\sigma_{0}\right)
$$

According to Equation [2], a linear relationship can be achieved between $\ln (\sigma)$ and $\ln [\ln (1 / 1-P)]$. It should be noted that the data value of $\ln (\sigma)$ need to be arranged in ascending order before performing linear fitting. The slope and intercept of the linear fitting formula are the Weibull modulus $m$ and the characteristic strength $\sigma_{0}$, respectively. Taking the compressive strength of PVA-SHCC group as an example, its linear fitting curves and probability distributions are illustrated in Figure 5(a) and 5(b), respectively. It can be seen that the shape parameter $m$ is 40.68 and the scale parameter $\sigma_{0}$ is 37.1 . As illustrated in Figure 5(b), the strength value (36.8 MPa) corresponding to $P=0.5$ is employed as the compressive strength of PVA-SHCC. It is important to note that the experimental data analysis for compressive strength, compressive peak strain and compressive toughness in the following parts of this paper also used the above Weibull distribution method.

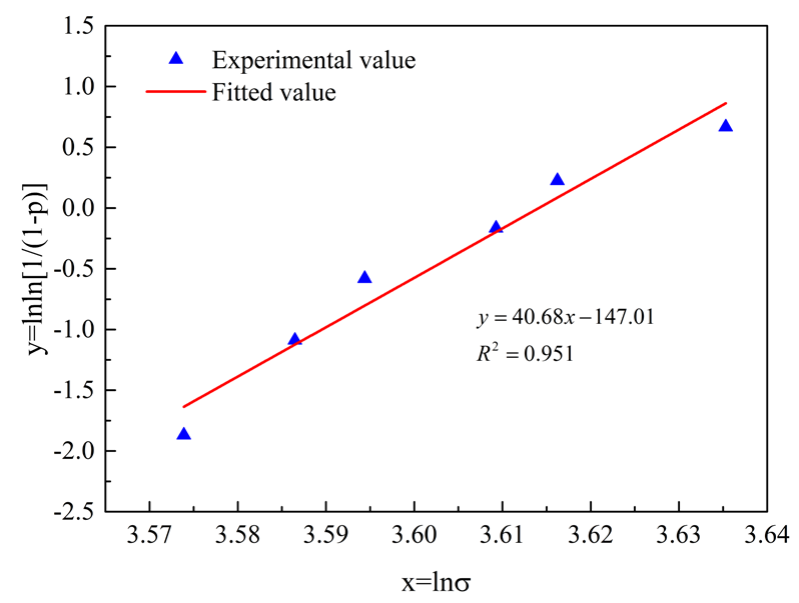

(a)

\section{RESULTS AND DISCUSSION}

\subsection{Compressive failure mode}

Figure 6 shows the compressive failure mode of PVA-SHCC and MsHySHCCs specimens after compression loading. Figure 7 presents the axial deformation $D_{a}$ and lateral deformation $D_{l}$ of specimen at 0.85 times peak stress. From Figure 6 , it can be observed that all the SHCC specimens display an extremely ductile performance under compression. The $D_{a}$ and $D_{l}$ values of all the designed MsHySHCCs in Figure 7 are lower than those of PVA-SHCC, which indicate the designed MsHySHCCs keeps a higher anti-deformability than PVA-SHCC due to the effective crack stabilization and fiber-bridging effects.

An in-depth analysis of Figure 7 shows that the hybrid use of hooked steel fiber and $\mathrm{CaCO}_{3}$ whisker has higher cracking control ability than PVA fiber, and a high content of steel fiber means a better anti-deformability, as have been widely discussed by previous literatures $(1,9-11)$. However, compared to MsHySHCC-1, MsHySHCC-2 and MsHySHCC-3, further decreasing the content of PVA fiber and increasing the content of $\mathrm{CaCO}_{3}$ whisker can't effectively improve the compressive behavior of SHCC (see MsHySHCC-4, MsHySHCC-5 and MsHySHCC-6). This implies that the macro fibers (e.g. steel fiber and PVA fiber) have stronger cracking control ability than that of micro fiber (e.g. $\mathrm{CaCO}_{3}$ whisker).

\subsection{Compressive stress-strain curves}

Typical compressive stress-strain curves of control groups, PVA-SHCC and MsHySHCCs are shown in Figure 8. Figure 9 summarizes the average compressive stress-strain curves of each group. The

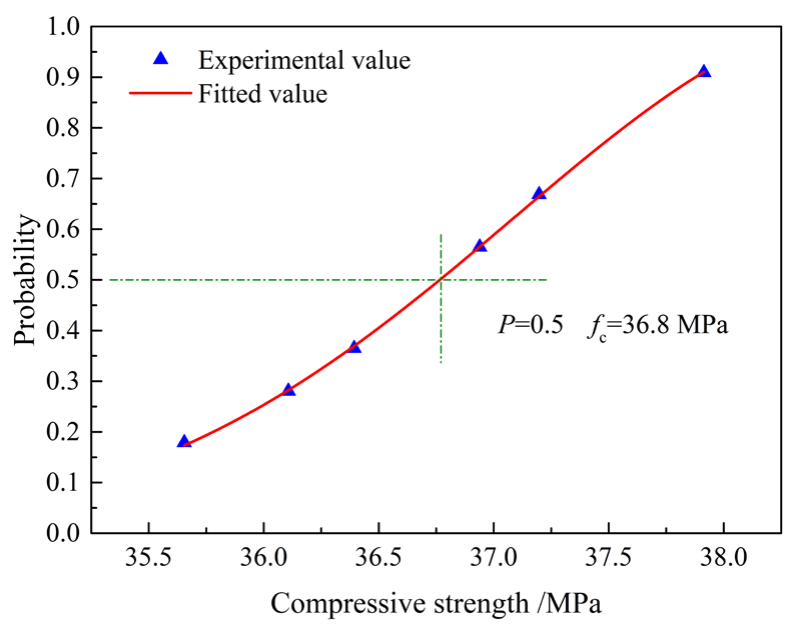

(b)

FIGURE 5. Linear fitting curves and probability distributions for the compressive strength of PVA-SHCC. 


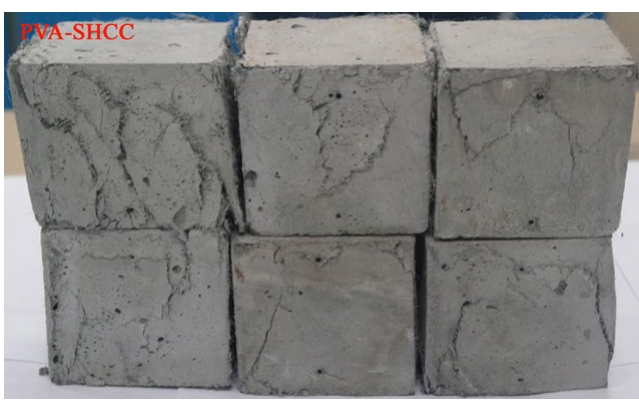

(a) PVA-SHCC

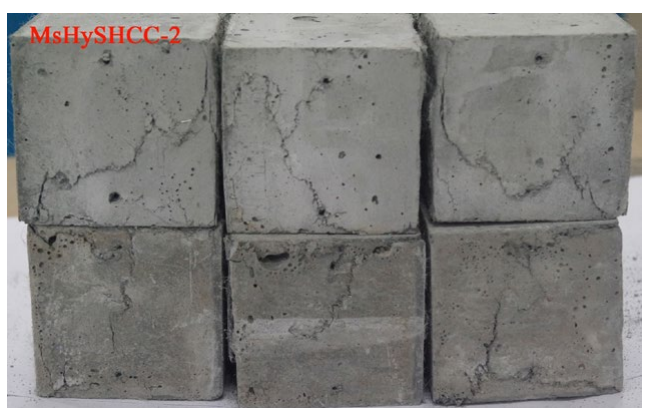

(c) MsHySHCC-2

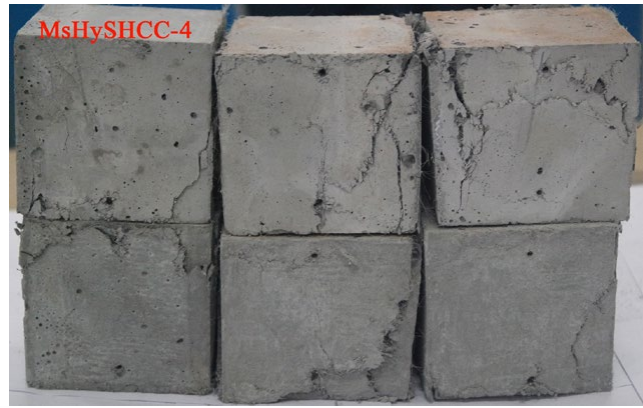

(e) MsHySHCC-4

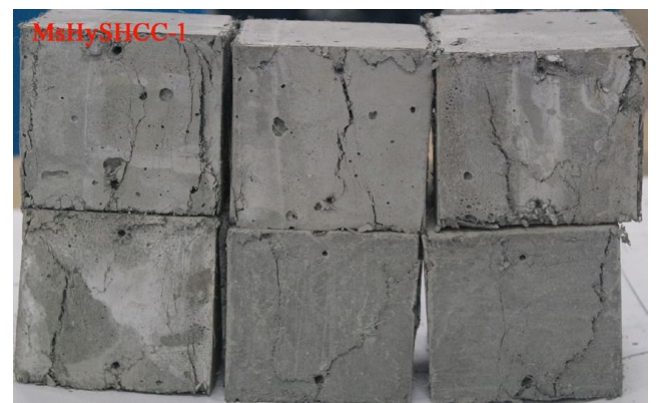

(b) MsHySHCC-1

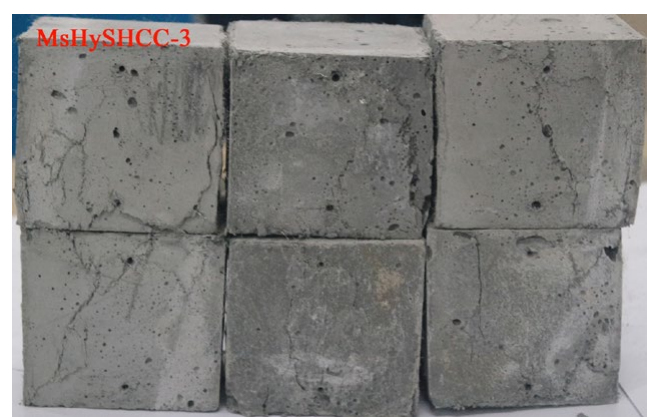

(d) MsHySHCC-3

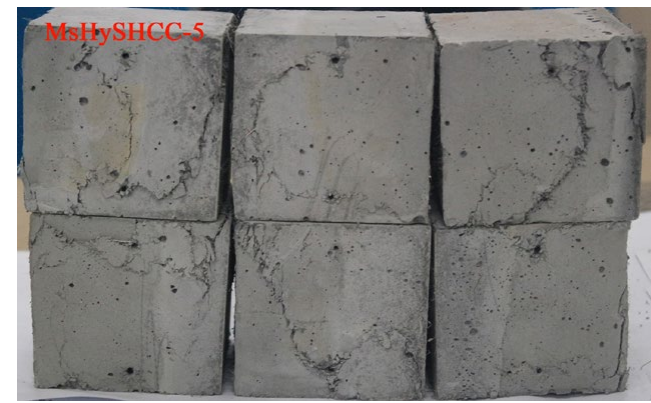

(f) MsHySHCC-5

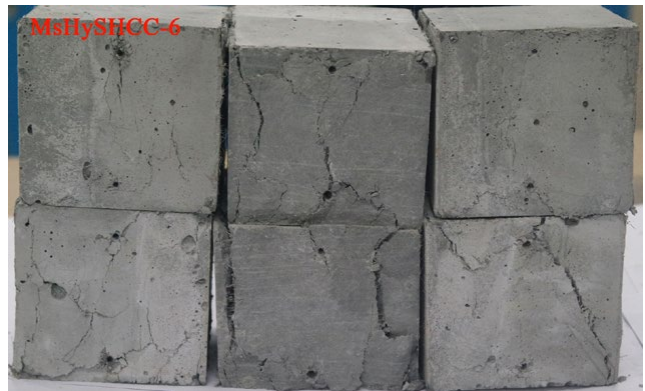

(g) MsHySHCC-6

Figure 6. Compressive failure mode of PVA-SHCC and MsHySHCCs specimens.

following results and discussions can be addressed:

(1) Compared to mortar matrix without whiskers, the introduction of $\mathrm{CaCO}_{3}$ whisker improves the compressive behavior due to the micro reinforcing mechanisms, such as whisker pullout, whisker bridging and crack deflection, as shown in Figure 10. Compared to control groups, the addition of macro fibers decreases the strength, but improves the postpeak behaviors of compression specimens.
(2) All the pre-peak curves are linear and elastic until about $40-60 \%$ of the peak, then the curves deviate from linear stage and become increasingly nonlinear up to the peak stress. Compared to PVA-SHCC, the ascending slop of MsHySHCCs increases slightly due to the high elastic modulus of steel fiber and $\mathrm{CaCO}_{3}$ whisker. In the descending stage, the MsHySHCCs has a relative higher residual stress value than that of PVA-SHCC due to the addition of hooked steel fi- 


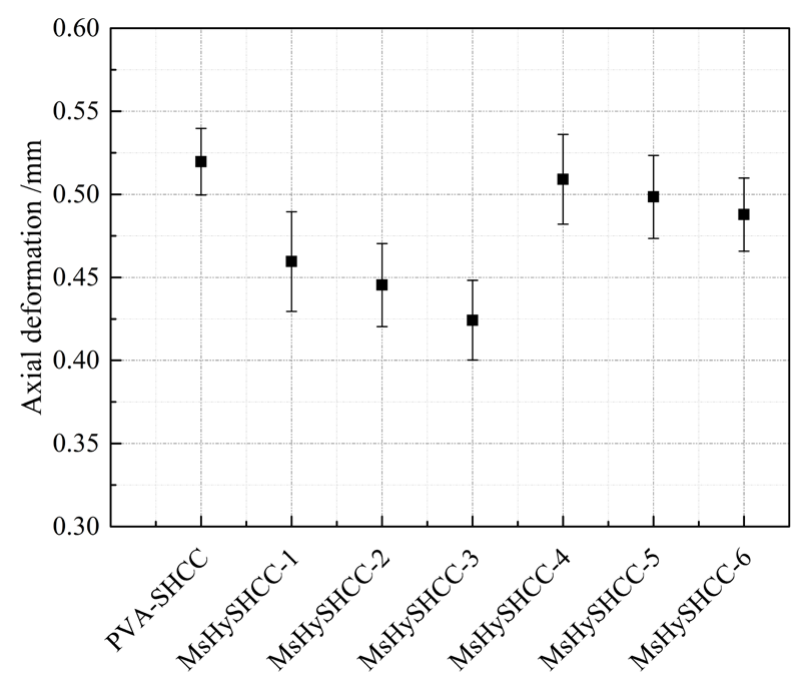

(a)

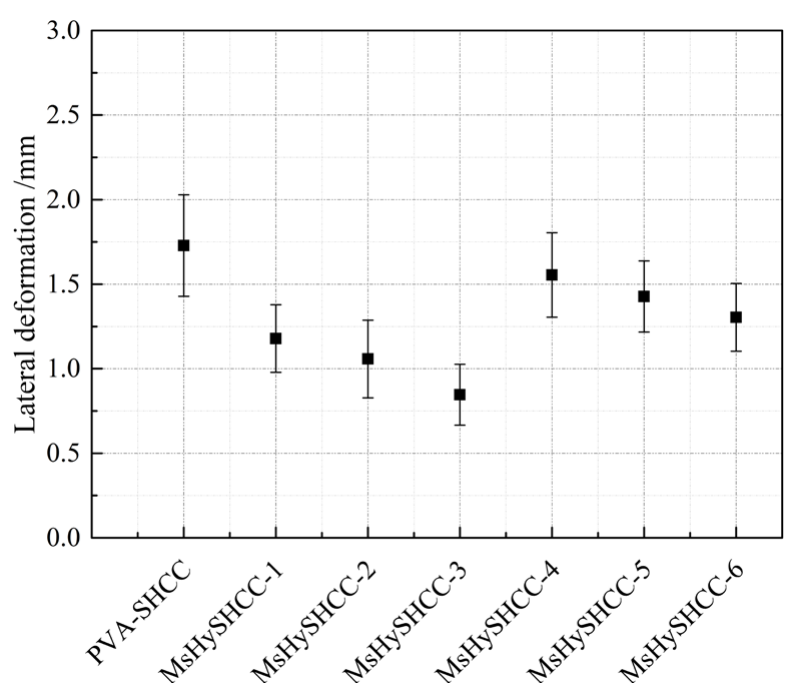

(b)

FiguRE 7. (a) Axial deformation and (b) lateral deformation at 0.85 times peak stress.

bers and $\mathrm{CaCO}_{3}$ whiskers, which can provide a better bridging effect than mono PVA fibers.

(3) Partially substituted PVA fibers by steel fibers and $\mathrm{CaCO}_{3}$ whiskers increased the compressive strength, as can be seen from Figure 8(d) $\sim(\mathrm{j})$ and Figure 9. Previous studies confirm that the use of micro steel fiber can enhance the shear capacity during cracking process, thus can increase the peak crack bridging stress contributed by steel fiber (1,9-11). Meanwhile, the addition of $\mathrm{CaCO}_{3}$ whisker can improve the compactness of composite and the micro reinforcing mechanisms presented in Figure 10 can also bring beneficial effect on the compressive strength $(15,23,26,27)$. Therefore, the compressive strength of MsHySHCCs is higher than that of PVA-SHCC.

(4) With the increase of steel fiber and $\mathrm{CaCO}_{3}$ whisker content, the descending stage becomes plumper, yielding higher residual load bearing capacity. This is because the steel fiber and $\mathrm{CaCO}_{3}$ whisker used in this study are rigid fiber with very high elastic modulus and stiffness. They can well hinder the growth and propagation of cracks, thus providing a significant improvement effect on residual load bearing capacity. Inversely, PVA fiber is a kind of flexible synthetic fiber, and its influence on the residual load bearing capacity is weaker than that of steel fiber and $\mathrm{CaCO}_{3}$ whisker.

\subsection{Compressive parameters}

Based on the compressive stress-strain curves in Figure 8 and Figure 9, compressive strength, compressive peak strain and compressive toughness of tested groups can be determined by Weibull distribution method mentioned in Section 2. Figure 11 displays the experimental results of compressive strength and compressive strain at peak stress. It can be seen that compared to mortar matrix without whiskers, the addition of $\mathrm{CaCO}_{3}$ whisker increases the compressive strength and compressive peak strain owing to the micro-mechanism in Figure 10. However, the introduction of macro fibers decreases the compressive strength and increases the compressive peak strain. Compared to PVA-SHCC, partially substituted PVA fiber by steel fiber and $\mathrm{CaCO}_{3}$ whisker improves the compressive strength but decreases the compressive peak strain. Increasing whisker content can further improve the compressive strength, although the content of PVA fiber is further decreased. The compressive peak strain of PVA-SHCC and MsHySHCCs ranges from 3200 to $4100 \mu \varepsilon$. The compressive peak strain of MsHySHCCs is smaller than that of PVA-SHCC, which implies that the MsHySHCCs have a higher elastic modulus, because the peak stress of MsHySHCCs is larger than that of PVA-SHCC. Furthermore, it seems that there is little correlation between the peak strain and the content of steel fibers or $\mathrm{CaCO}_{3}$ whiskers.

Compressive toughness is used to evaluate the energy absorption capacity of PVA-SHCC and MsHySHCCs under compression loading, which is numerically equal to the area enclosed under the stress-strain curve, also called strain energy, as given in Table 2. It can be seen that the addition of multi-scale fibers improves the pre-peak strain energy, post-peak strain energy and total strain energy compared to the mono use of PVA fibers. Consistent with the trend shown in the above compression failure photos, the higher the content of steel fiber, the greater the compression toughness value, as shown in Figure 12(a). But further substituted PVA fibers by $\mathrm{CaCO}_{3}$ whiskers can't further significantly increase the compressive toughness of MsHySHCCs, as shown in Figure 12(b). 


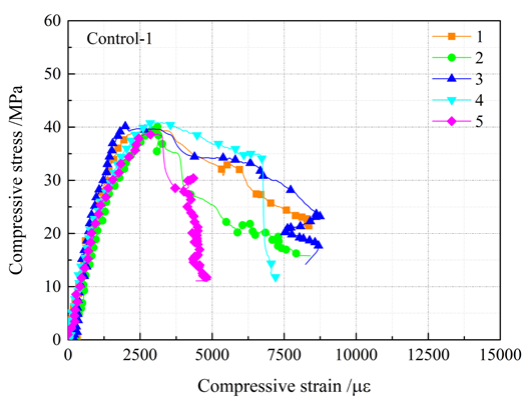

(a)

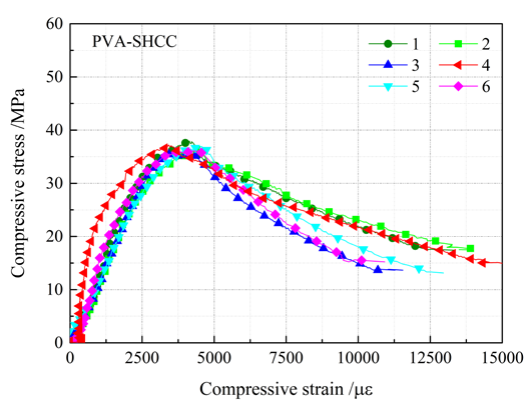

(d)

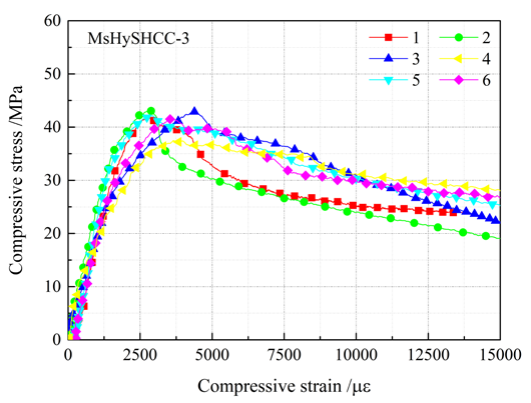

(g)

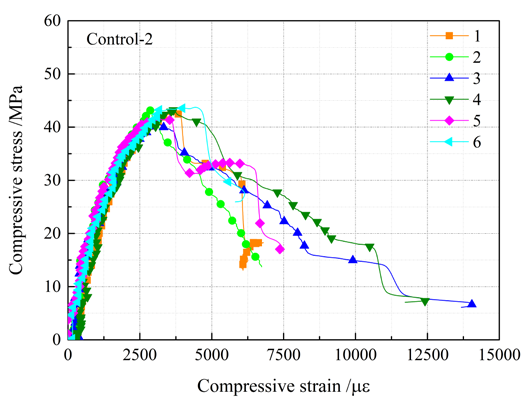

(b)

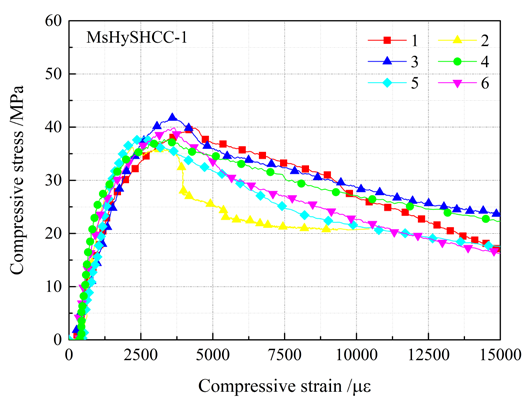

(e)

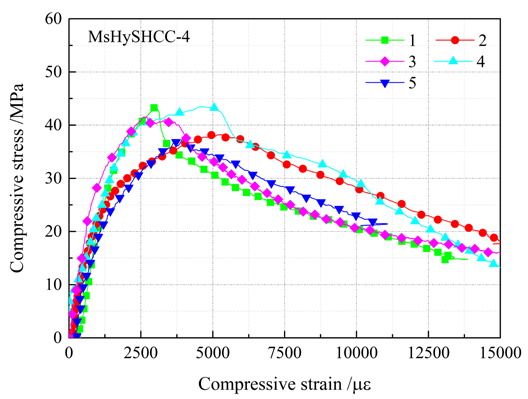

(h)

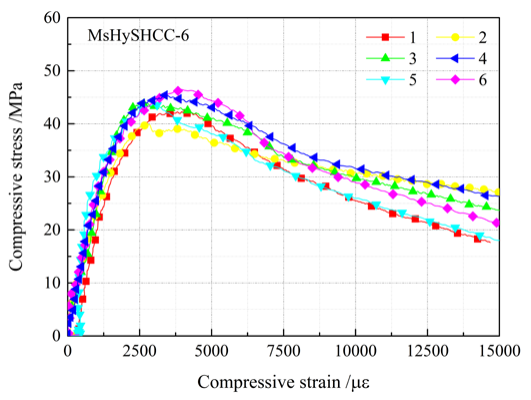

(j)

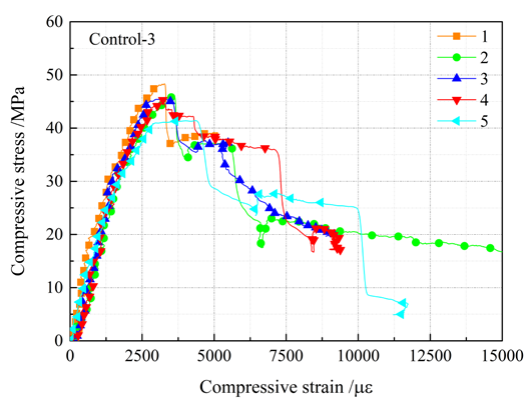

(c)

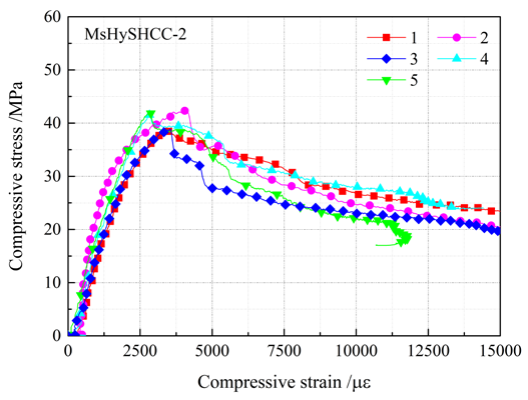

(f)

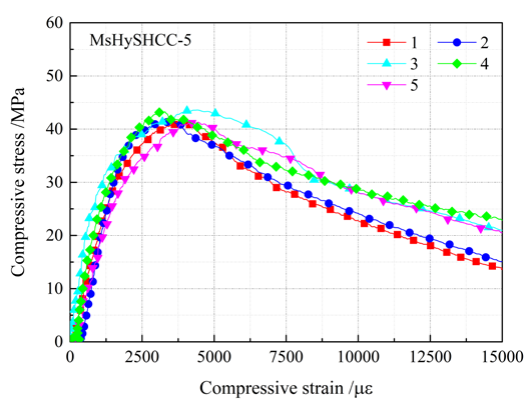

(i)

FIGURE 8. Compressive stress-strain curves of tested specimens.

\subsection{Compression constitutive model}

\subsubsection{Model-1: Damage constitutive model}

Based on the strain equivalent principle, previous literatures state that the compressive damage constitutive model of plain concrete can be expressed as Equation [3], (32, 33).

$$
\sigma=E \varepsilon \exp \left[-\frac{1}{m}\left(\frac{\varepsilon}{\varepsilon_{p k}}\right)^{m}\right]
$$

where $\sigma$ is the compressive stress of concrete, $\mathrm{MPa} ; E$ is the elastic modulus of concrete, $\mathrm{GPa} ; \varepsilon$ is the compressive strain of concrete; $\varepsilon_{p k}$ is the peak compressive strain; $m$ is the shape parameter, which can be calculated by Equation [4]. 


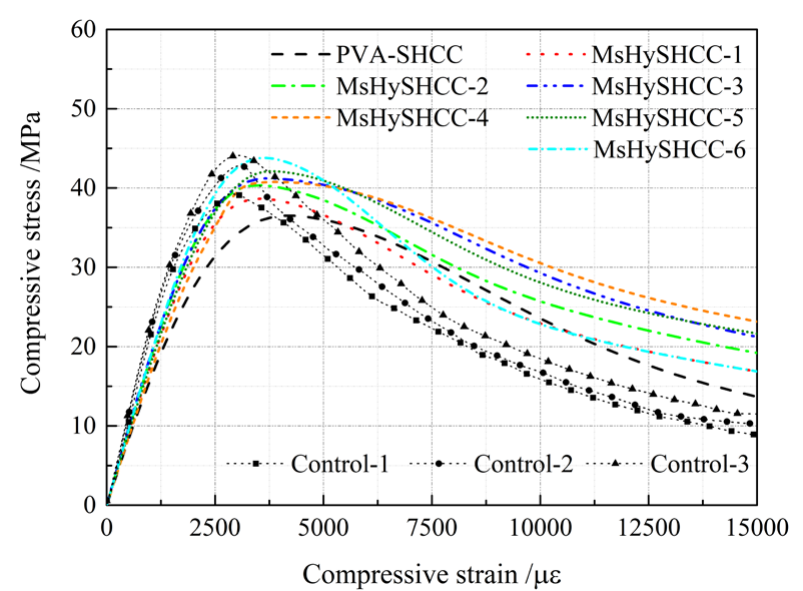

FIGURE 9. Summary results of average compressive stress-strain curves.

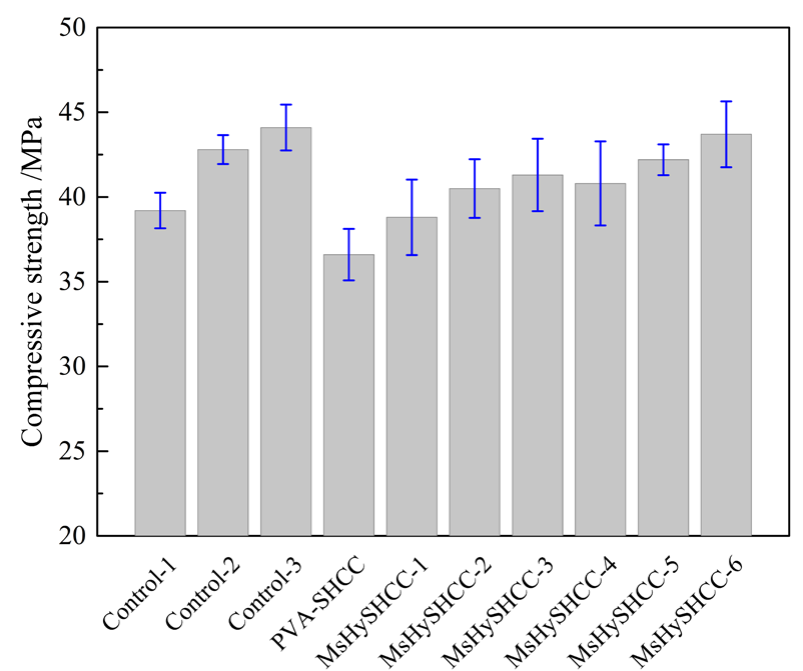

(a)

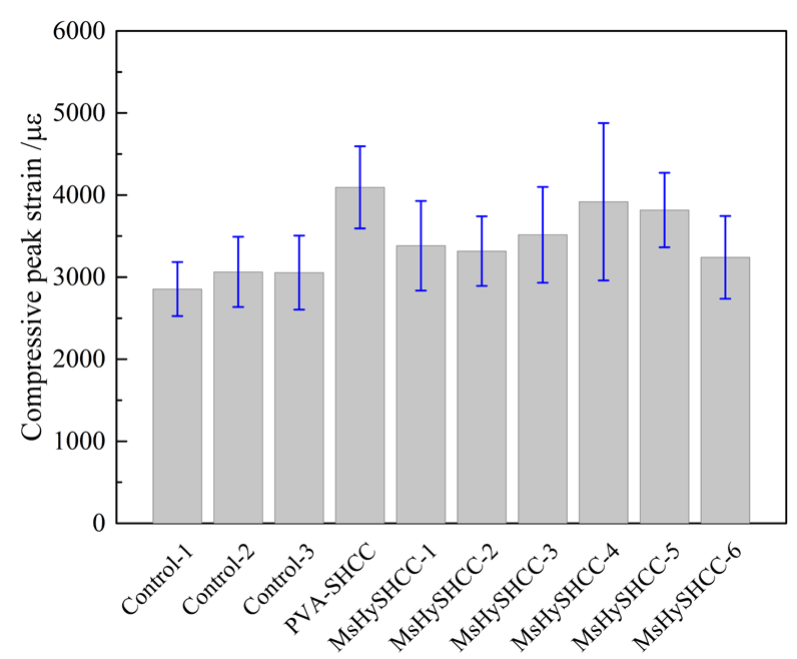

(b)

FIGURE 11. Experimental results of (a) compressive strength and (b) compressive peak strain.

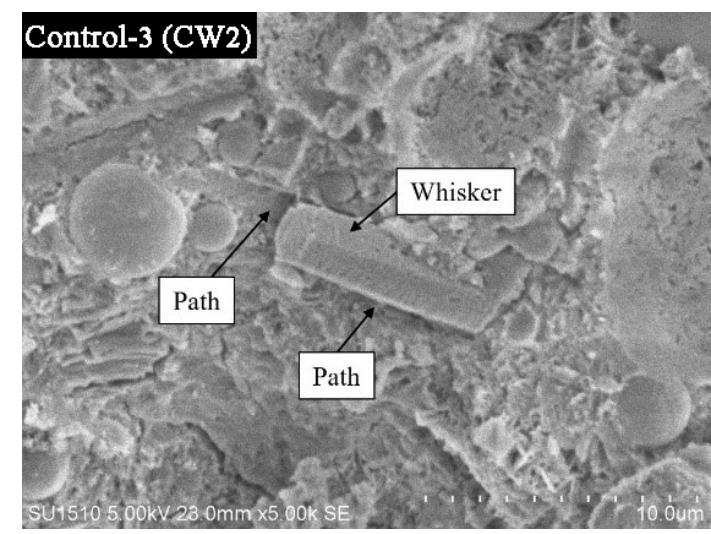

(a)

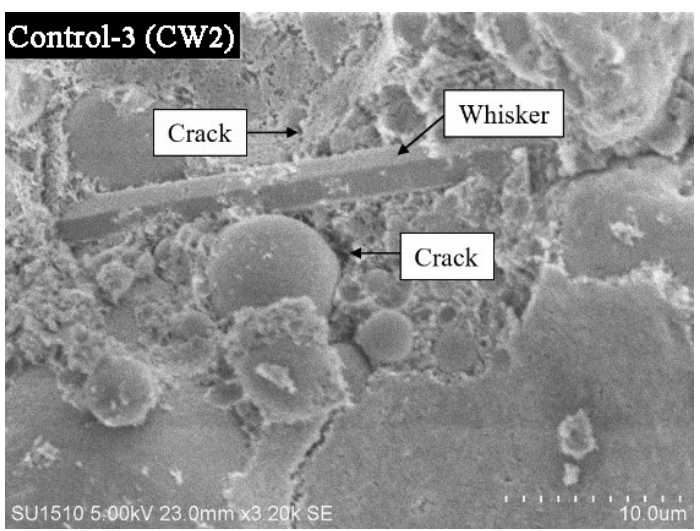

(b)

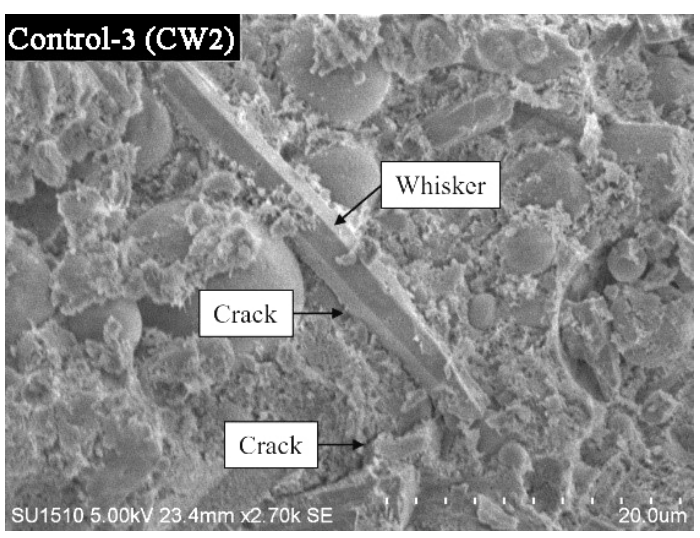

(c)

Figure 10. SEM images showing: (a) whisker pullout; (b) whisker bridging; (c) crack deflection.

$$
m=\frac{1}{\ln \left(\frac{E \varepsilon_{p k}}{f_{p k}}\right)}
$$

where $f_{p k}$ is the compressive strength (peak compressive stress), MPa.

However, to fiber-reinforced cementitious composite, the addition of fibers improves the compressive toughness of cementitious composite, thus mak- 


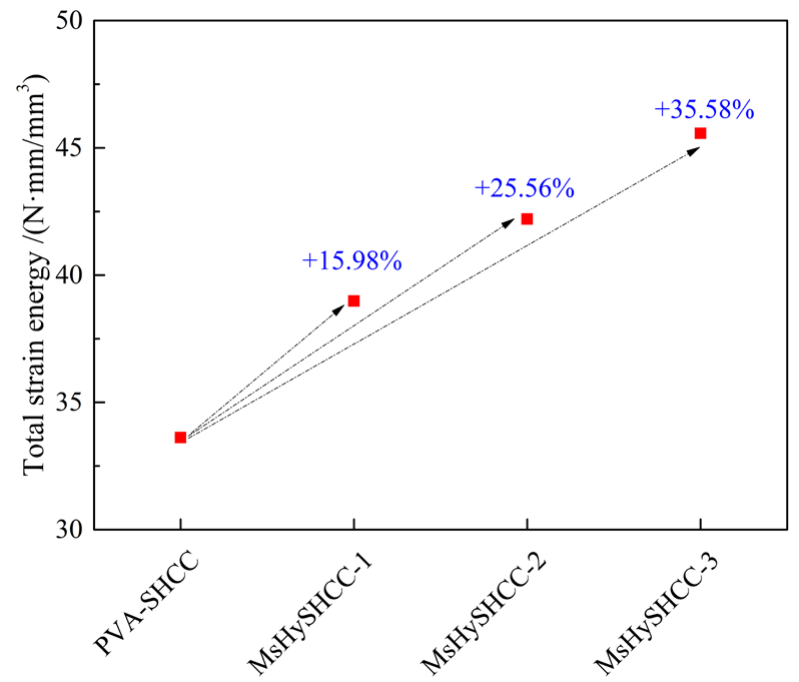

(a)

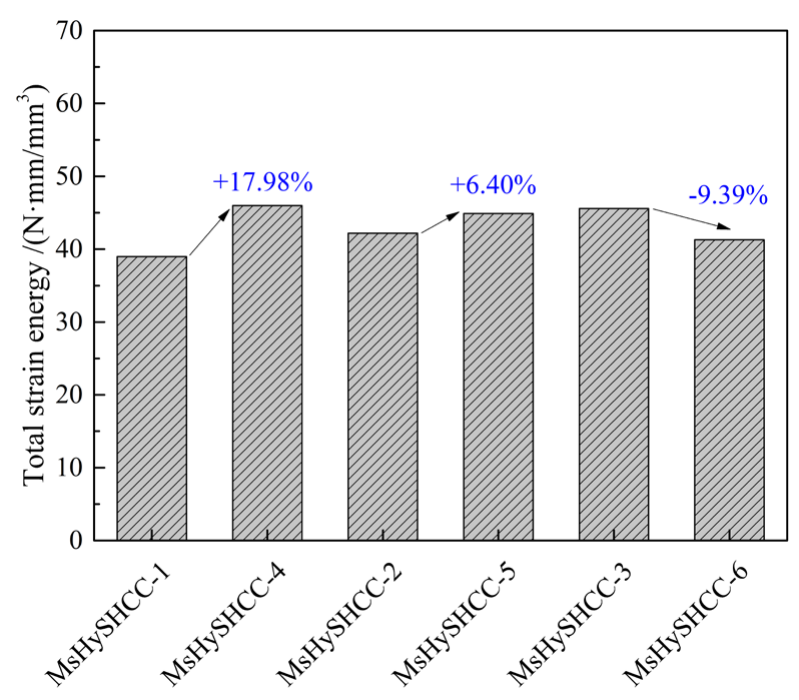

(b)

Figure 12. Comparison of total strain energy for PVA-SHCC and MsHySHCCs.

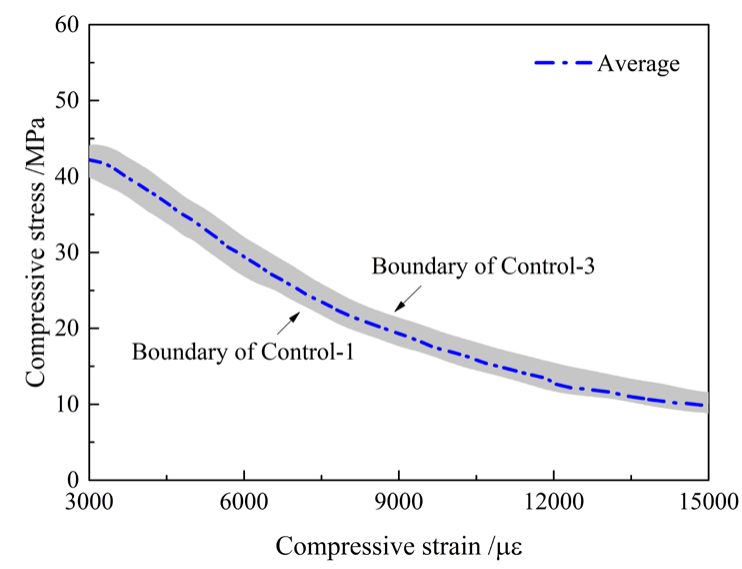

(a)
TABLE 2. Compressive toughness for PVA-SHCC and MsHySHCCs.

\begin{tabular}{ccccc}
\hline Groups & $\begin{array}{c}\text { Pre-peak } \\
\text { strain } \\
\text { energy } \\
/(\mathrm{N} \cdot \mathrm{mm} / \\
\left.\mathrm{mm}^{3}\right)\end{array}$ & $\begin{array}{c}\text { Post-peak } \\
\text { strain } \\
\text { energy } \\
/(\mathrm{N} \cdot \mathrm{mm} / \\
\left.\mathrm{mm}^{3}\right)\end{array}$ & $\begin{array}{c}\text { Total } \\
\text { strain } \\
\text { energy } \\
(\mathrm{N} \cdot \mathrm{mm} / \\
\left.\mathrm{mm}^{3}\right)\end{array}$ & $\begin{array}{c}\text { Relative } \\
\text { toughness } \\
\text { index }\end{array}$ \\
\hline $\begin{array}{c}\text { PVA- } \\
\text { SHCC }\end{array}$ & 6.92 & 24.38 & 33.61 & 1.00 \\
\hline $\begin{array}{c}\text { MsHy- } \\
\text { SHCC-1 }\end{array}$ & 7.64 & 31.80 & 38.98 & 1.16 \\
\hline $\begin{array}{c}\text { MsHy- } \\
\text { SHCC-2 }\end{array}$ & 7.94 & 34.06 & 42.20 & 1.26 \\
\hline $\begin{array}{c}\text { MsHy- } \\
\text { SHCC-3 }\end{array}$ & 7.73 & 34.58 & 45.47 & 1.35 \\
\hline $\begin{array}{c}\text { MsHy- } \\
\text { SHCC-4 }\end{array}$ & 7.31 & 25.66 & 45.99 & 1.37 \\
\hline $\begin{array}{c}\text { MsHy- } \\
\text { SHCC-5 }\end{array}$ & 6.83 & 28.40 & 44.90 & 1.34 \\
\hline $\begin{array}{c}\text { MsHy- } \\
\text { SHCC-6 }\end{array}$ & 7.41 & 31.74 & 41.29 & 1.23 \\
\hline
\end{tabular}

ing the compressive stress-strain curves plumper. Therefore, a fiber reinforcing factor $R I_{v}$ is employed in the above model to consider the effect of volume and geometrical characteristic of fibers (34). And $R I_{v}$ can be expressed as Equation [5].

$$
R I_{v}=\sum_{i=1}^{n} \beta V_{i} \frac{l_{i}}{d_{i}}\left(\frac{E_{i}}{E_{s f}}\right)^{p}
$$

where $n=2$ (two types of macro fibers, i.e. steel fiber and PVA fiber); $\beta$ is the fiber bonding coefficient (35), taken as 1 and 1.2 for PVA fiber and hooked steel fiber, respectively; $p$ is a dimensionless parameter, taken as 1.3 and 1 for PVA fiber and hooked

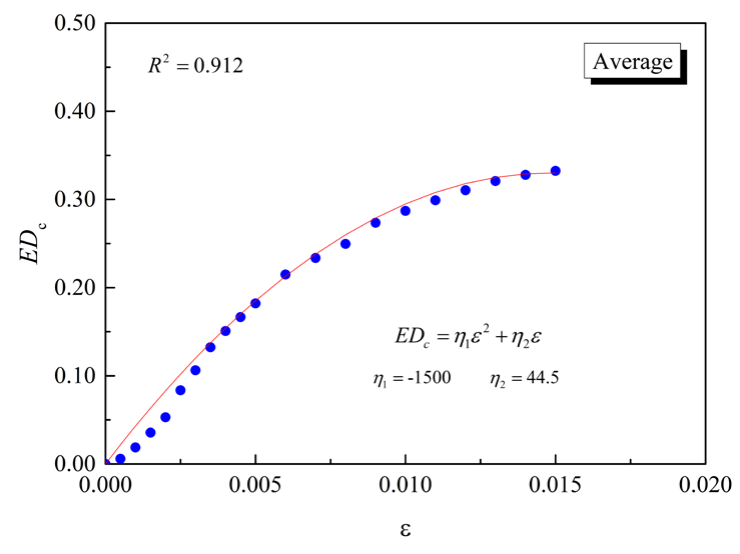

(b)

FIgURE 13. (a) Average post-peak curve for control groups; (b) relationship of $E D_{c}$ and $\mathcal{E}$. 


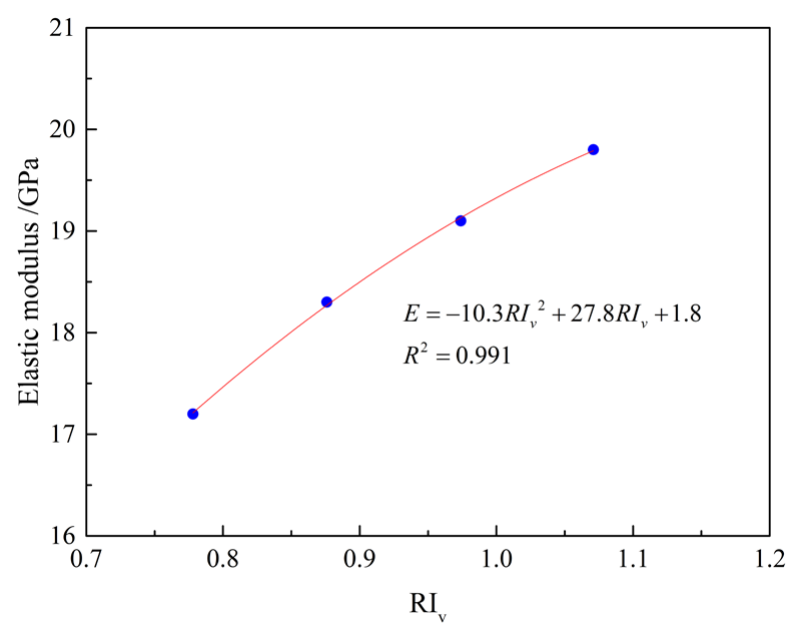

(a)

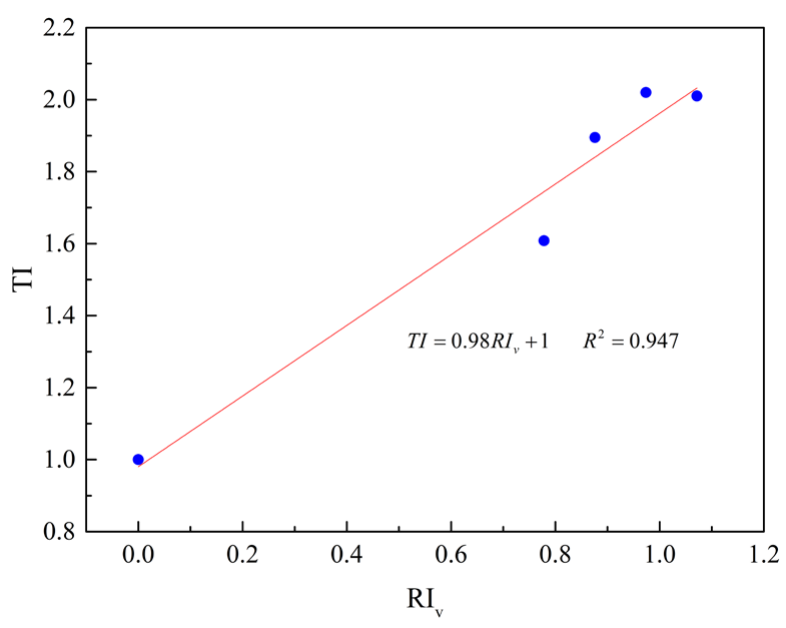

(b)

FIGURE 14. Relationship of (a) $E$ and $R I_{v}$; (b) $T I$ and $R I_{v}$.

steel fiber, respectively; $V_{i}$ is the volume content of fiber $i, \% ; l_{i}$ is the length of fiber $i, \mathrm{~mm} ; d_{i}$ is the diameter of fiber $i, \mathrm{~mm} ; E_{i}$ is elastic modulus of fiber $i$, $\mathrm{GPa} ; E_{s f}$ is the elastic modulus of steel fiber, $\mathrm{GPa}$, as shown in Figure 1.

To PVA-SHCC and MsHySHCCs, the post-peak load decreases more slowly and the energy absorption capacity is higher. In order to describe the postpeak stress-strain relationship more accurately, an energy method was employed in this paper to describe the post-peak strain behavior. According to Ou and Tsai's study (34), the toughness index TI was used to consider the effect of fibers on the compressive toughness of cementitious composite. And TI can be calculated by Equation [6].

$$
T I=\frac{E D}{E D_{c}}
$$

where $E D$ is the energy absorption capacity of PVA-SHCC and MsHySHCCs, which is numerically equal to the area enclosed under the stress-strain curve; $E D_{c}$ is the energy absorption capacity of control mortar, which can be integrated through the stress-strain curves in Figure 13. Moreover, according to Ezeldin's suggestion (33), $E D$ and $E D_{c}$ can be defined as the area enclosed under the compressive stress-strain curve when the compressive strain is 0.015 .

In this paper, the relationship between elastic modulus $E$ and fiber reinforcing index $R I_{v}$ is shown in Figure 14(a). The relationship between toughness index $T I$ and fiber reinforcing index $R I_{v}$ is shown in Figure 14(b).

The post-peak compressive stress-strain relationship of PVA-SHCC and MsHySHCCs can be expressed as Equation [7].

$$
\sigma=E \varepsilon \exp \left[-\frac{1}{m}\left(\frac{\varepsilon}{\varepsilon_{p k}}\right)^{m}\right]+k \frac{(T I-1) E D_{c}}{\varepsilon}
$$

Where $k$ is an enhancement coefficient, which is employed to represent the enhancement effect of fibers on the post-peak residual stress. And $k$ can be expressed as Equation [8].

$$
k=1-E \varepsilon \exp \left[-\frac{1}{m}\left(\frac{\varepsilon}{\varepsilon_{p k}}\right)^{m}\right] / \sigma_{p k}
$$

Therefore, the compressive stress-strain relationship of PVA-SHCC and MsHySHCCs can be expressed as Equation [9].

$$
\sigma=\left\{\begin{array}{l}
E \varepsilon \exp \left[-\frac{1}{m}\left(\frac{\varepsilon}{\varepsilon_{\mathrm{pk}}}\right)^{m}\right] \quad 0 \leq \varepsilon \leq \varepsilon_{\mathrm{pk}} \\
E \varepsilon \exp \left[-\frac{1}{m}\left(\frac{\varepsilon}{\varepsilon_{\mathrm{pk}}}\right)^{m}\right]+k \frac{(T I-1) E D_{c}}{\varepsilon} \quad \varepsilon>\varepsilon_{\mathrm{pk}}
\end{array}\right.
$$

Figure 15 shows the comparison between experimental result and theoretical result calculated by model-1. It can be observed that the proposed model-1 can well calculate and predict the compressive constitutive relationships of PVA-SHCC and MsHySHCCs.

\subsubsection{Model-2: Geometrical constitutive model}

Many current specifications have given the geometrical mathematical equations to describe the ascending and descending curves of compressive 


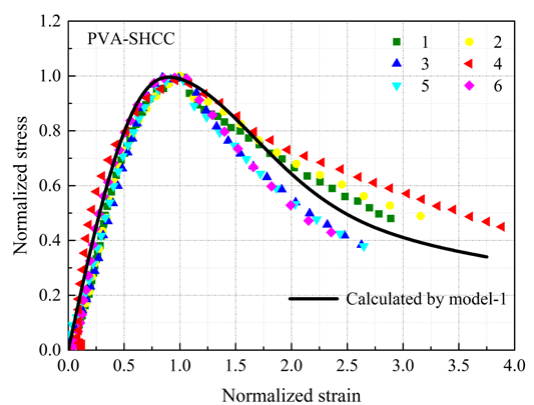

(a)

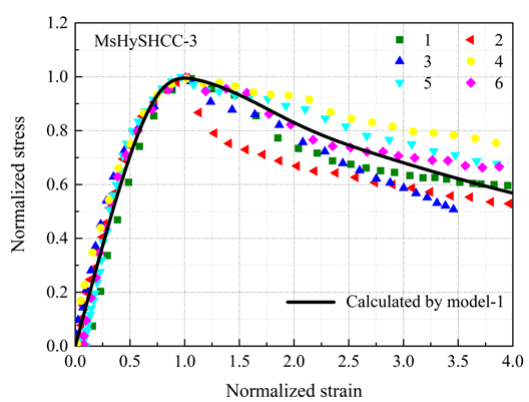

(c)

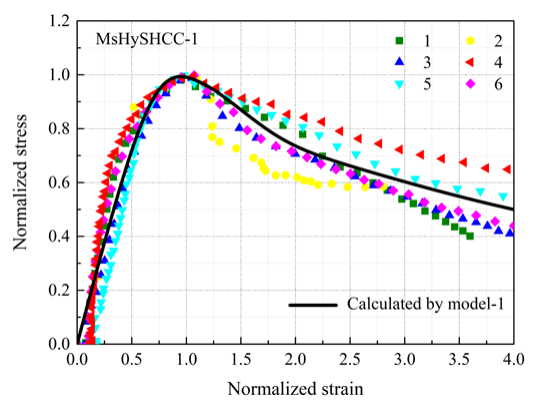

(b)

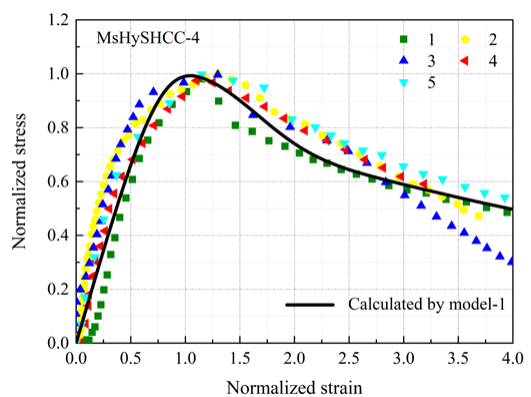

(d)

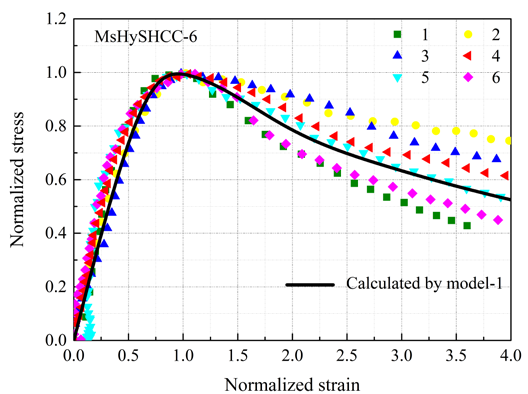

(f)

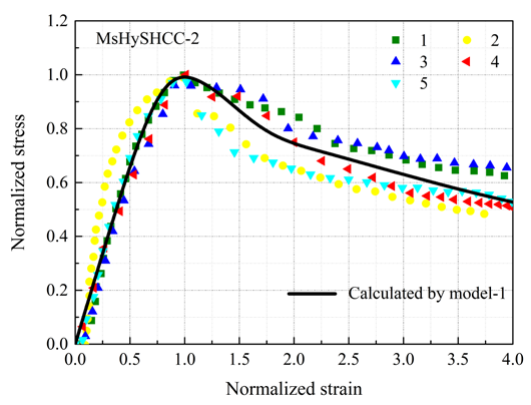

(b)

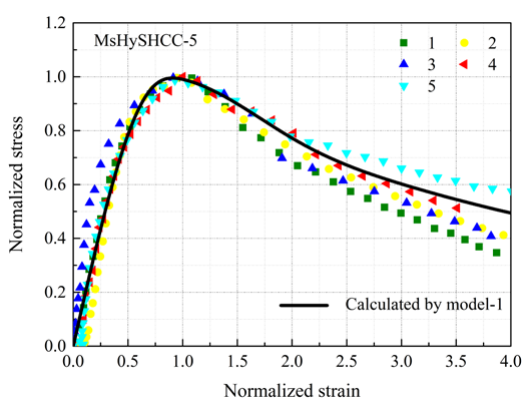

(e)

FIGURE 15. Comparison between experimental result and theoretical result calculated by model-1.

constitutive relationship of normal concrete, as presented in Equation [10], Equation [11] and Equation [12].

$$
\begin{gathered}
\sigma=\left\{\begin{array}{c}
E \varepsilon \frac{\rho_{c} n}{n-1+x^{n}} \quad 0 \leq \varepsilon \leq \varepsilon_{\mathrm{pk}} \\
E \varepsilon \frac{\rho_{c}}{\alpha_{c}(x-1)^{2}+x} \quad \varepsilon>\varepsilon_{\mathrm{pk}}
\end{array}\right. \\
\rho_{c}=\frac{f_{p k}}{E \varepsilon_{p k}} \text { and } x=\frac{\varepsilon}{\varepsilon_{p k}} \\
n=\frac{E \varepsilon_{p k}}{E \varepsilon_{p k}-f_{p k}}
\end{gathered}
$$

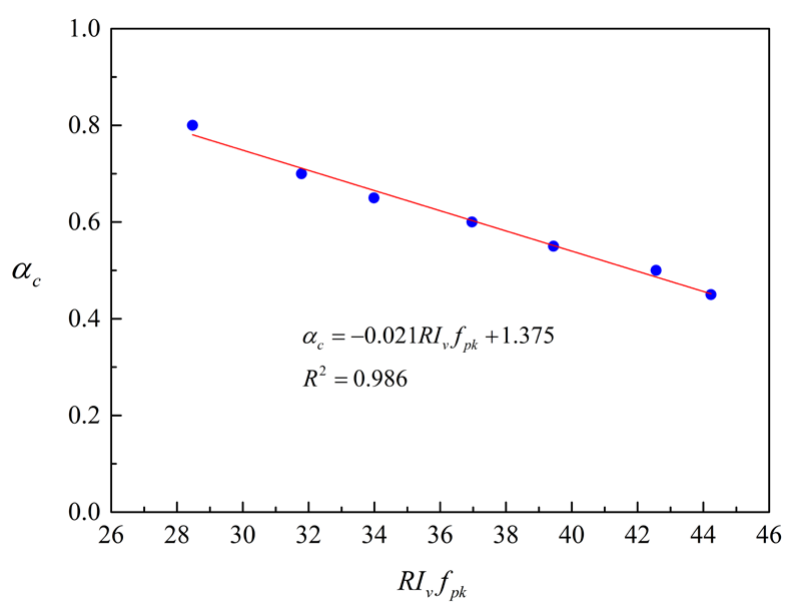

FIGURE 16. Relationship between $\alpha_{c}$ and $R I_{v} f_{p k}$. 


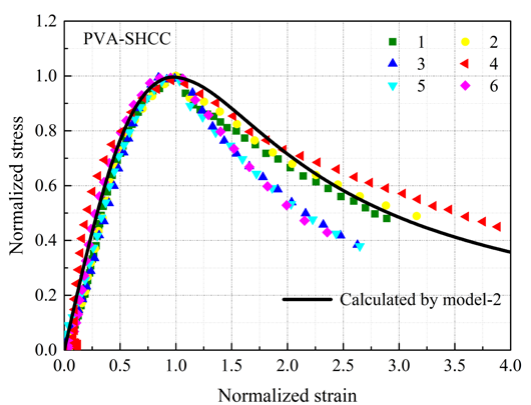

(a)

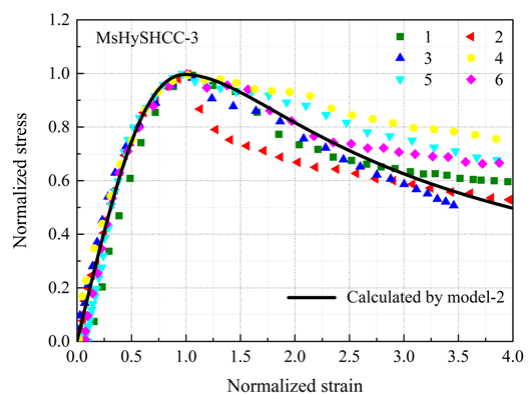

(c)

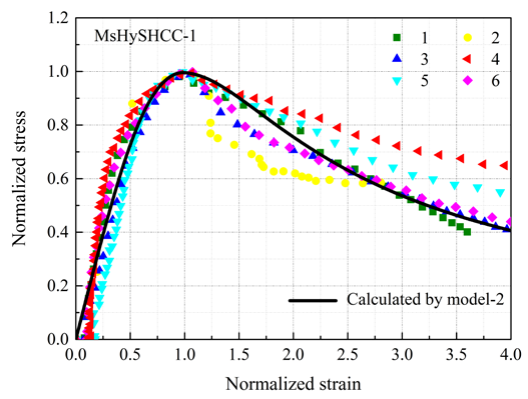

(b)

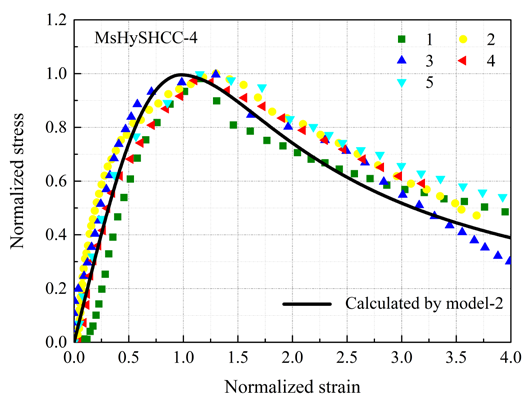

(d)

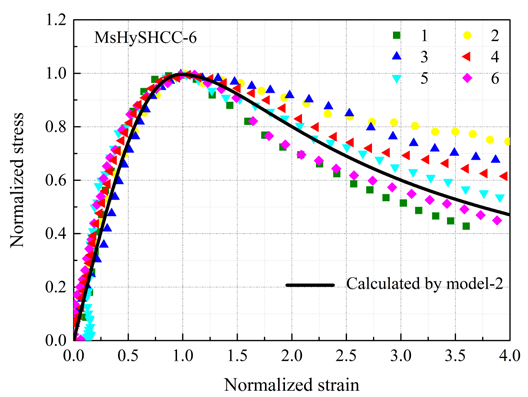

(f)

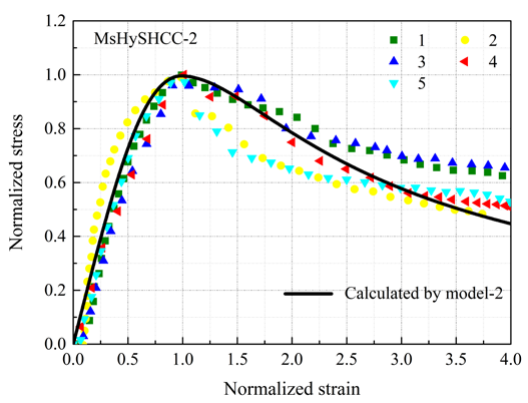

(b)

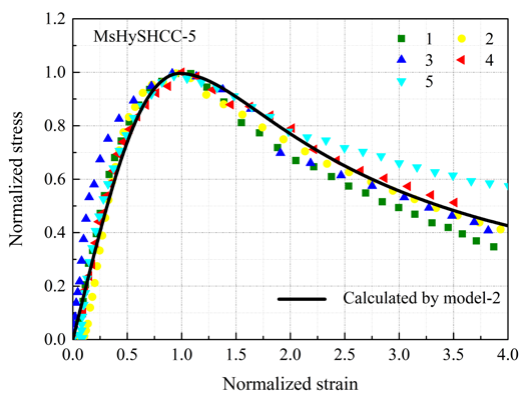

(e)

FIgURE 17. Comparison between experimental result and theoretical result calculated by model-2.

where $E$ is the elastic modulus of designed composite and $E=-10.3 R I_{v}^{2}+27.8 R I_{v}+1.8$, as shown in Figure $14(\mathrm{a}) ; \alpha_{c}$ is the dimensionless parameter to describe the descending characteristics of compressive stress-strain curves.

Compared to normal concrete, PVA-SHCC and MsHySHCC will obtain a higher post-peak residual bearing capacity due to the addition of fibers. Therefore, the descending parameter $\alpha$ of PVA-SHCC and MsHySHCC will be different from that of normal concrete. And obviously, $\alpha$ is directly related to the fiber reinforcing index $R I_{v}$. Based on the experimental results and regression analysis, the relationship between $\alpha_{c}$ and $R I_{v} f_{p k}$ can be illustrated in Figure 16.

Figure 17 presents the comparison between experimental result and theoretical result calculated by model-2. It can be seen that the proposed model-2 can also well calculate and predict the compressive constitutive relationships of PVA-SHCC and MsHySHCCs. Compared to damage constitutive model (model-1), this geometrical constitutive model (model-2) is more concise, but it lacks the mechanism description to some extent. Nevertheless, both of the proposed models can be applied to predict the uniaxial compressive stress-strain relationships of PVA-SHCC and MsHySHCCs.

\section{CONCLUSIONS}

Compressive behaviors of multi-scale fiber reinforced strain hardening cementitious composite (MsHySHCC) were investigated experimentally in this paper. From this study, the following conclusions can be addressed. 
The addition of $\mathrm{CaCO}_{3}$ whisker increased the compressive strength and toughness of mortar matrix by the micro-mechanism of whisker pull-out, whisker bridging and crack deflection, thus improved the compressive performance of MsHySHCC.

(2) The hybrid use of hooked steel fiber and $\mathrm{CaCO}_{3}$ whisker had higher cracking control ability than PVA fiber, and a high content of steel fiber means a better anti-deformability. Moderately partially substituted PVA fibers by steel fiber and $\mathrm{CaCO}_{3}$ whisker can enhance the compressive behaviors of PVA-SHCC. But excessive reduction of PVA fiber content will degrade the compressive performance of MsHySHCC.

(3) Based on the experimental data, a damage constitutive model and a geometrical mathematical model were proposed semi-theoretically. Through the comparison between experimental results and theoretical results calculated by these two models, it can be found that both of the models can well calculate and predict the compressive constitutive relationships of PVA-SHCC and MsHySHCC. The geometrical constitutive model is more concise, but the damage constitutive model can describe the damage and reinforcing mechanism to some extent.

\section{ACKNOWLEDGEMENTS}

The Natural Science Foundation of China (51908247) and the Opening Project of State Key Laboratory for GeoMechanics and Deep Underground Engineering (KFJJ202007) are gratefully acknowledged by the authors.

\section{AUTHOR CONTRIBUTIONS:}

Conceptualization: C. Zhang. Funding acquisition: C. Zhang. Investigation: C. Zhang, Z. Yuan, Y. Shen. Methodology: Z. Yuan, Y. Shen. Validation: C. Zhang, Z. Yuan, Y. Shen. Roles/Writing, original draft: C. Zhang. Writing, review \& editing: C. Zhang.

\section{REFERENCES}

1. Liu, T.; Yang, Y.; Chen, Z.; Li, Y.; Bai, R. (2020) Optimization of fiber volume fraction to enhance reinforcing efficiency in hybrid fiber reinforced strain hardening cementitious composite. Cem. Concr. Comp. 113, 103704. https://doi. org/10.1016/j.cemconcomp.2020.103704.

2. Gesoglu, M.; Güneyisi, E.; Muhyaddin, G.F.; Asaad, D.S. (2016) Strain hardening ultra-high performance fiber reinforced cementitious composites: Effect of fiber type and concentration. Compos. Part B-Eng. 103, 74-83. https://doi. org/10.1016/j.compositesb.2016.08.004.

3. Yu, K-Q.; Lu, Z-D.; Dai, J-G.; Shah, S.P. (2020) Direct tensile properties and stress-strain model of UHP-ECC. $J$. Mater. Civil Eng. 32 [1], 0419334. https://doi.org/10.1061/ (ASCE)MT.1943-5533.0002975.

4. Ding, Y.; Yu, J-t.; Yu, K-Q.; Xu, S-L. (2018) Basic mechanical properties of ultra-high ductility cementitious composites: From $40 \mathrm{MPa}$ to $120 \mathrm{MPa}$. Compos. Struct. 185, 634-645. https://doi.org/10.1016/j.compstruct.2017.11.034.

5. Pan, Z.; Wu, C.; Liu, J.; Wang, W.; Liu, J. (2015) Study on mechanical properties of cost-effective polyvinyl alcohol engineered cementitious composites (PVA-ECC). Constr. Build. Mater. 78, 397-404. https://doi.org/10.1016/j. conbuildmat.2014.12.071.

6. Felekoglu, B.; Tosun-Felekoglu, K.; Ranade, R.; Zhang, Q.; Li, V.C. (2014) Influence of matrix flowability, fiber mixing procedure, and curing conditions on the mechanical performance of HTPP-ECC. Compos. Part B-Eng. 60, 359370. https://doi.org/10.1016/j.compositesb.2013.12.076.

7. CHoi, W-C.; Yun, H-D.; Kang, J-W.; Kim, S-W. (2012) Development of recycled strain-hardening cement-based composite (SHCC) for sustainable infrastructures. Compos. Part B-Eng. 43 [2], 627-635. https://doi.org/10.1016/j. compositesb.2011.11.060.

8. Maalej, M.; Quek, S.T.; Ahmed, S.F.U.; Zhang, J.; Lin, V.W.J.; Leong, K.S. (2012) Review of potential structural applications of hybrid fiber Engineered Cementitious Composites. Constr. Build. Mater. 36, 216-227. https://doi. org/10.1016/j.conbuildmat.2012.04.010.

9. Pourfalah, S. (2018) Behaviour of engineered cementitious composites and hybrid engineered cementitious composites at high temperatures. Constr. Build. Mater. 158, 921-937. $\mathrm{https://doi.org/10.1016/j.conbuildmat.2017.10.077.}$

10. Wang, Z.; Zuo, J.; Zhang, X.; Jiang, G.; Feng, L. (2018) Stress-strain behaviour of hybrid-fibre engineered cementitious composite in compression. Adv. Cem. Res. 32 [2], 1-21. https://doi.org/10.1680/jadcr.18.00072.

11. Al-Gemeel, A.; Yan, Z.; Osama, Y. (2018) Use of hollow glass microspheres and hybrid fibres to improve the mechanical properties of engineered cementitious composite. Constr. Build. Mater. 171, 858-870. https://doi.org/10.1016/j. conbuildmat.2018.03.172.

12. Cao, M.L.; Liu, Z.X.; Xie, C.P. (2020) Effect of steel-PVA hybrid fibers on compressive behavior of $\mathrm{CaCO}_{3}$ whiskers reinforced cement mortar. J. Build. Eng. 31, 101314. https:// doi.org/10.1016/j.jobe.2020.101314.

13. Xie, C.P.; Cao, M.L.; Si, W.; Khan, M. (2020) Experimental evaluation on fiber distribution characteristics and mechanical properties of calcium carbonate whisker modified hybrid fibers reinforced cementitious composites. Constr. Build. Mater. 265, 120292. https://doi.org/10.1016/j. conbuildmat.2020.120292.

14. Cao, M.; Xie, C.; Guan, J. (2019) Fracture behavior of cement mortar reinforced by hybrid composite fiber consisting of $\mathrm{CaCO}_{3}$ whiskers and PVA-steel hybrid fibers. Compos. Part A-Appl. S. 120, 172-187. https://doi.org/10.1016/j. compositesa.2019.03.002.

15. Li, L.; Cao, M.; Xie, C.; Yin, H. (2019) Effects of $\mathrm{CaCO}_{3}$ whisker, hybrid fiber content and size on uniaxial compressive behavior of cementitious composites. Struct. Concrete. 20 [1], 506-518. https://doi.org/10.1002/ suco.201800185.

16. Cao, M.L.; Xie, C.P.; Li, L.; Khan, M. (2019) Effect of different PVA and steel fiber length and content on mechanical properties of $\mathrm{CaCO}$ whisker reinforced cementitious composites. Mater. Construcc. 69 [336], e200. https://doi. org/10.3989/mc.2019.12918.

17. Cao, M.L.; Xu, L.; Zhang, C. (2018) Rheological and mechanical properties of hybrid fiber reinforced cement mortar. Constr. Build. Mater. 171, 736-742. https://doi. org/10.1016/j.conbuildmat.2017.09.054.

18. Cao, M.L.; Li, L. (2018) New models for predicting workability and toughness of hybrid fiber reinforced cementbased composites. Constr. Build. Mater. 176, 618-628. https:// doi.org/10.1016/j.conbuildmat.2018.05.075.

19. Cao, M.L.; Li, L.; Khan, M. (2018) Effect of hybrid fibers, calcium carbonate whisker and coarse sand on mechanical properties of cement-based composites. Mater. Construcc. 68 [330], e156. https://doi.org/10.3989/mc.2018.01717.

20. Cao, M.L.; Li, L.; Zhang, C. (2018) Behaviour and damage assessment of a new hybrid-fibre-reinforced mortar under impact load. Mag. Concrete Res. 70 [17], 905-918. https:// doi.org/10.1680/jmacr.16.00536.

21. Li, L.; Cao, M. (2018) Influence of calcium carbonate whisker and polyvinyl alcohol-steel hybrid fiber on ultrasonic velocity and resonant frequency of cementitious composites. Constr. Build. Mater. 188, 737-746. https://doi.org/10.1016/j. conbuildmat.2018.08.154 
22. Cao, M.L.; Xie, C.P.; Li, L. (2018) The relationship between reinforcing index and flexural parameters of new hybrid fiber reinforced slab. Comput. Concrete. 22 [5], 481-492. https:// doi.org/10.12989/cac.2018.22.5.481.

23. Cao, M.L.; Zhang, C.; Li, Y.; Wei, J. (2015) Using calcium carbonate whisker in hybrid fiber-reinforced cementitious composites. J. Mater. Civil Eng. 27 [4], 1-13. https://doi. org/10.1061/(ASCE)MT.1943-5533.0001041.

24. Zhang, C.; Cao, M.L. (2014) Fiber synergy in multi-scale fiberreinforced cementitious composites. J. Reinf. Plast. Comp. 33 [9], 862-874. https://doi.org/10.1177/0731684413514785.

25. Cao, M.L.; Zhang, C.; Lv, H.F. (2014) Mechanical response and shrinkage performance of cementitious composites with a new fiber hybridization. Constr. Build. Mater. 57, 45-52. https://doi.org/10.1016/j.conbuildmat.2014.01.088.

26. Ma, H.; Cai, J.M.; Lin, Z · Qian, S ; Li, V.C. (2017) CaCO whisker modified engineered cementitious composite with local ingredients. Constr. Build. Mater. 151, 1-8. https://doi. org/10.1016/j.conbuildmat.2017.06.057.

27. Pan, J.L.; Cai, J.M.; Ma, H.; Leung, C.K.Y. (2018) Development of multiscale fiber-reinforced engineered cementitious composites with PVA Fiber and $\mathrm{CaCO}_{3}$ whisker. J. Mater. Civil Eng. 30 [6], 04018106. https://doi. org/10.1061/(ASCE)MT.1943-5533.0002305.

28. Zhou, J.; Pan, J.; Leung, C. (2015) Mechanical behavior of fiber-reinforced engineered cementitious composites in uniaxial compression. J. Mater. Civil Eng. 27 [1], 1-10. https://doi.org/10.1061/(ASCE)MT.1943-5533.0001034.

29. Yu, K-Q.; Yu, J-T.; Dai, J-G.; Lu, Z-D.; Shah, S.P. (2018) Development of ultra-high performance engineered cementitious composites using polyethylene (PE) fibers. Constr. Build. Mater. 158, 217-227. https://doi.org/10.1016/j. conbuildmat.2017.10.040

30. Xu, S.; Cai, X. (2010) Experimental study and theoretical models on compressive properties of ultra-high toughness cementitious composites. J. Mater. Civil Eng. 22 [10], 1067-1077. https://doi. org/10.1061/(ASCE)MT.1943-5533.0000109.

31. Yun, H-D. (2013) Effect of accelerated freeze-thaw cycling on mechanical properties of hybrid PVA and PE fiberreinforced strain-hardening cement-based composites (SHCCs). Compos. Part B-Eng. 52, 11-20. https://doi. org/10.1016/j.compositesb.2013.03.021.

32. Lemaitre, J. (1984) How to use damage mechanics. Nucl. Eng. Des. 80 [2], 233-245. https://doi.org/10.1016/00295493(84)90169-9.

33. Ezeldin, A.; Balaguru, P. (1992) Normal and high-strength fiber reinforced concrete under compression. J. Mater. Civil Eng. 4 [4], 415-429. https://doi.org/10.1061/(ASCE)08991561(1992)4:4(415)

34. Ou, Y-C.; Tsai, M-S.; Liu, K-Y.; Chang, K-C. (2012) Compressive behavior of steel-fiber-reinforced concrete with a high reinforcing index. J. Mater. Civil Eng. 24 [2], 207-215. https://doi.org/10.1061/(ASCE)MT.19435533.0000372 .

35. Ning, X.; Ding, Y.; Zhang, F.; Zhang, Y. (2015) Experimental Study and prediction model for flexural behaviour of reinforced SCC beam containing steel fibers. Constr. Build. Mater. 93, 644-653. https://doi.org/10.1016/j. conbuildmat.2015.06.024 